\title{
Umbilical cord cyst: a diagnostic dilemma
}

\section{Aayushi Kaushal*, Reeti Mehra, Sunita Dubey, Poonam Goel, Seema Sheokand, Navjot Kaur}

Department of Obstetrics and Gynaecology, GMCH Sector 32, Chandigarh, Punjab, India

Received: 27 October 2018

Accepted: 28 November 2018

\section{*Correspondence:}

Dr. Aayushi Kaushal,

E-mail: kaushalaayushi@gmail.com

Copyright: (c) the author(s), publisher and licensee Medip Academy. This is an open-access article distributed under the terms of the Creative Commons Attribution Non-Commercial License, which permits unrestricted non-commercial use, distribution, and reproduction in any medium, provided the original work is properly cited.

\section{ABSTRACT}

Umbilical cord cyst refers to any cystic lesion associated with the umbilical cord. Cord cysts can be defined as true or false cysts and may occur in any location along the cord. They are irregular in shape and are located between the cord vessels. Authors are reporting the case of an infant with an umbilical cord tumor which had twice been misdiagnosed previously as a hemangioma, based on ultrasound image of its cystic and solid component with good vascular supply. The ultrasound image most likely suggestive of a hemangioma as a differential diagnosis led to caesarean section in our patient (based on large size of the lesion and fear of rupture of same during process of labour). The definitive diagnosis was made only after birth of the baby. Final diagnosis of true umbilical cord cyst was made after histopathological examination. Thus, there can be confusion in the diagnosis between umbilical cord hemangiomas and umbilical cord cysts based on ultrasound.

Keywords: Umbilical cord, Umbilical cord cyst, Umbilical cord hemangioma

\section{INTRODUCTION}

Umbilical cord cysts are classified as true cysts and pseudocysts, the latter being more common. Although they can occur at any location along the umbilical cord, they are usually located towards its fetal insertion. They are irregular in shape and located between the vessels. ${ }^{1,2}$

True cysts are small remnants of the allantois (allantoid cysts) or the umbilical vesicle. Cysts have epithelial lining of flat or cuboidal uroepithelium. They can grow up to several centimetres but more often range between 4 and $60 \mathrm{~mm}$ in size. True cysts can be associated with hydronephrosis, patent urachus, omphalocele and Meckel diverticulum. $^{3,4}$ False cysts (pseudocysts) are more common. They come from liquefaction of Wharton jelly and may be as large as $6 \mathrm{~cm}$. Compared with the true cysts, the pseudocysts do not have epithelial lining. Pseudocysts may be associated with chromosomal anomalies, omphalocele, hemangiomas and patent urachus. ${ }^{5}$ Regardless the type of the cord cysts, $20 \%$ of them are associated with structural or chromosomal anomalies, especially trisomies 18 and 13 .

The pre-natal differential diagnosis of umbilical cord tumours include pseudocysts, omphalo-mesenteric duct cysts, vascular disorders, abdominal wall defects, teratomas, bladder exstrophy and urachal anomalies.

A definitive ultrasonic diagnosis may not always be possible to differentiate between cysts, hemangiomas and other lesions and may lead to inevitable caesarean sections and other complications.

\section{CASE REPORT}

A 25-year-old primigravida was referred to our outpatient department at 26 weeks period of gestation with ultrasound report showing complex cystic lesion in umbilical cord most likely hemangioma. Patient had not 
undergone nuchal translucency/nasal bone scan, and neither were the dual and quadruple markers got done. She had a report of level two ultrasound at 20 weeks which showed mixed solid cystic lesion of $5 * 5 \mathrm{~cm}$ at site of origin of umbilical cord from placenta encasing the umbilical cord vessels most likely hemangioma. No gross congenital malformation of fetus was noted. Fetal ECHO had been done which was normal. AFP levels were advised by some practitioner at 26 weeks which were highly raised $(912 \mathrm{ng} / \mathrm{ml})$. Normal range for that gestation was $39-179 \mathrm{ng} / \mathrm{ml}$.

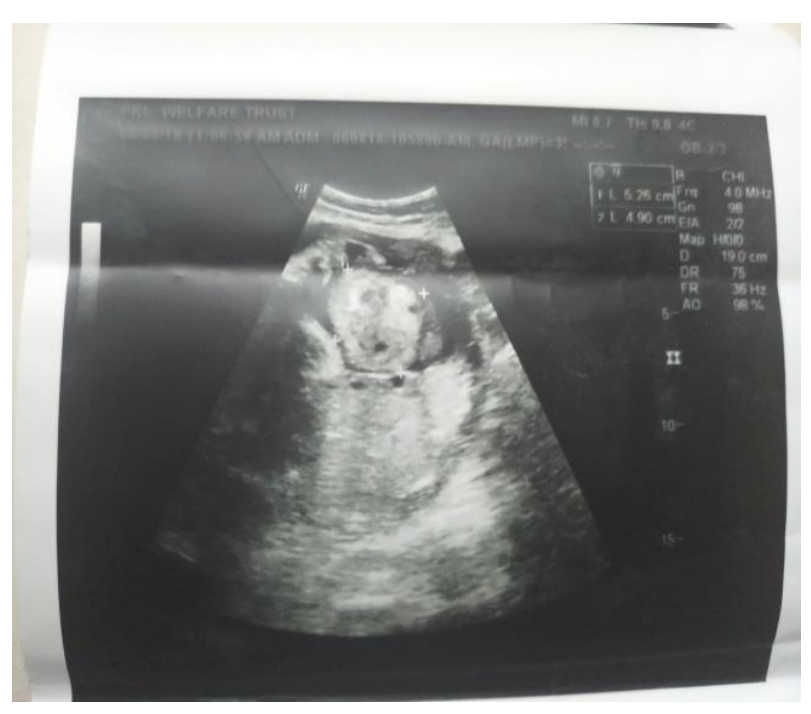

Figure 1: Ultrasound showing solid component of the mass.

At our institute repeat ultrasound was performed at 28 weeks showed that showed increased size of the lesion $9.6 * 8.7 \mathrm{~cm}$ floating in amniotic fluid. Outline of the mass was well defined. Internal echotexture was coarse and showed large cystic areas with few of them showing thin septations and a solid bright component $5.3 * 5.1 \mathrm{~cm}$ (Figure 1 and 2).

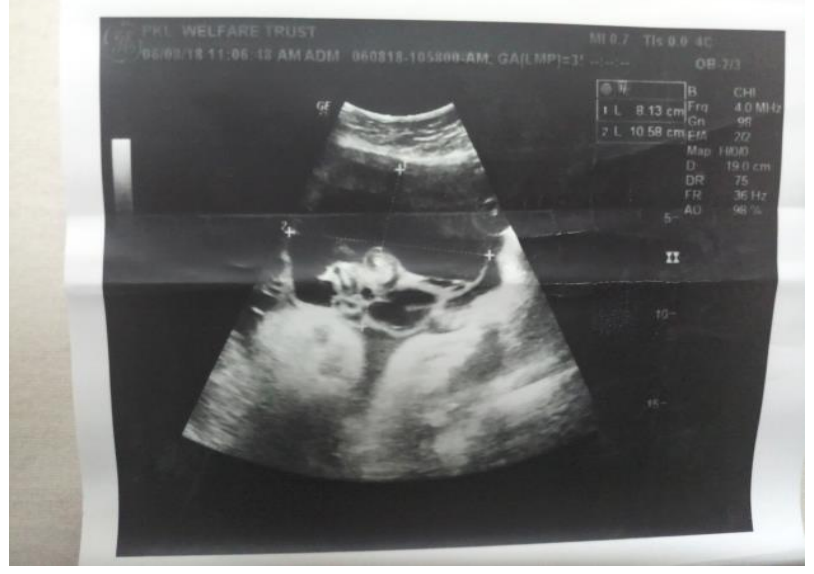

Figure 2: Ultrasound showing cystic component of the mass.
Medial part showed umbilical vessels traversing inside with good vascular flow. USG also showed polyhydramnios (AFI 18). Fetal biometry was consistent with dates. Umbilical artery shows good diastolic flow without any decrease or reversal. There was no obvious gross congenital malformation. She had an uneventful pregnancy and underwent elective LSCS at 39 weeks. Decision for LSCS was taken in view of large vascular lesion possibly hemangioma $(10 * 10 \mathrm{~cm})$ and fear of rupture of same during process of labour.

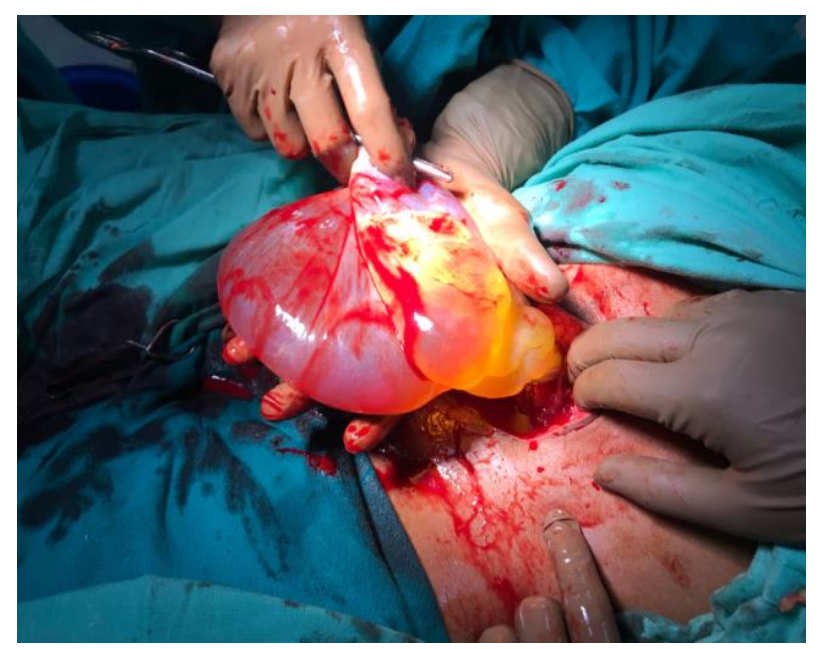

Figure 3: Cyst being taken out.

A female baby weighing 3300 grams was born. The infant had an APGAR score of 9 and 9 in the $1^{\text {st }}$ and $5^{\text {th }}$ minutes, respectively. The cord was tied with a clamp quite far from the umbilicus with the concern that an intestinal segment could exist in the cord sac (keeping in view of omphalocele and umbilical hernias as differential diagnosis).

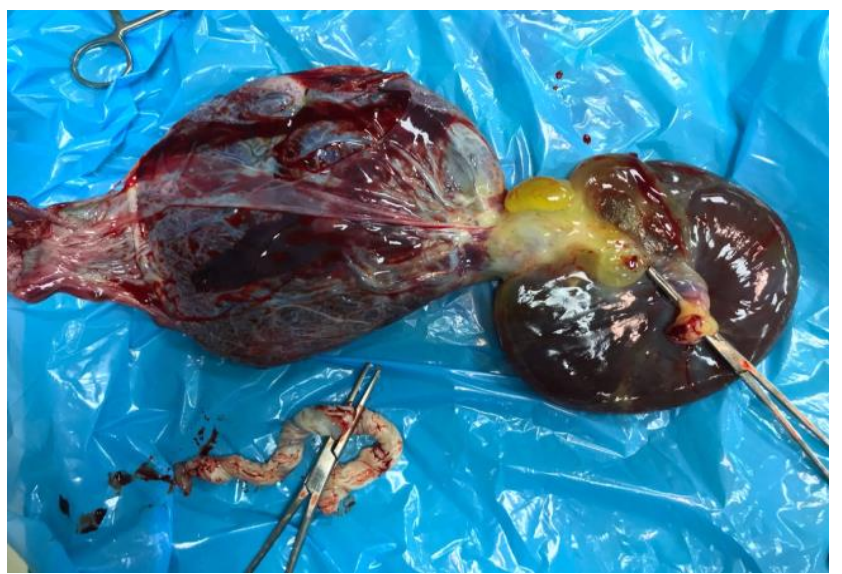

Figure 4: Cyst (on right side) at placental end.

There was a large cystic structure near placental end of umbilical cord (Figure 3and 4). After a repeated careful examination, the umbilical cord mass was detected to contain no intestinal segment or any patent duct since it was translucent. At the entrance of the cord to the 
umbilicus, the diameter was nearly the size of a normal cord. No karyotyping could be performed because the mother did not agree to such an investigation. The macroscopic examination revealed an umbilical cord of $40-\mathrm{cm}$ in length and diameter $0.2-2.5 \mathrm{~cm}$ in diameter, containing 1 vein and 2 arteries. On gross examination cyst was identified at base of umbilical cord measuring $7.5 \mathrm{~cm}$ maximum diameter near the placental end (Figure 3 and 4). Wall thickness measured $0.1-0.2 \mathrm{~cm}$. On cutting open mucoid material admixed with blood came out. The histopathological investigation revealed umbilical cord cyst which had fibrocollagenic wall focally lined by flattened epithelium. Wall shows minimal chronic inflammation. No evidence of hemangioma was noted. The examination of the placenta detected no pathology (weight 300gm). The infant had congenital hemangiomatosis (Figure 5).

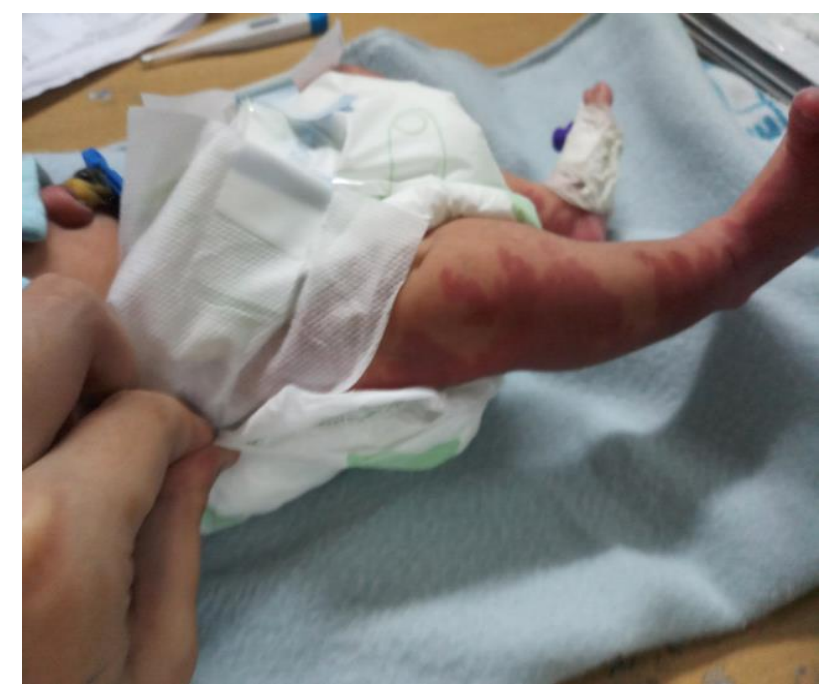

Figure 5: Hemangiomas over thigh.

\section{DISCUSSION}

The prenatal differential diagnosis of umbilical cord tumour include pseudocysts, omphalos-mesenteric duct cysts, vascular disorders, abdominal wall defects, bladder exstrophy and urachal anomalies. Umbilical cord cysts are commonly classified as true cysts and pseudocysts. True cysts are derived from the embryological remnants of either the allantois or the omphalos-mesenteric duct when partial or complete absence of obliteration of this structures occurs true cysts have an epithelial lining, actually a flat or cuboidal uroepithelium. ${ }^{6}$ Usually microscopic and with no clinical relevance, they can grow up to several centimeters. ${ }^{6,7}$ True cysts are very rare and they are typically located near the fetal cord insertion. Allantoic cysts resolve themselves but may be associated with patent urachus, omphalocele, and possibly, obstructive uropathy. Cysts in the omphalosmesenteric duct can be associated with defects in the abdominal wall and with Meckel's diverticulum. Amniotic inclusion cysts are lined by amniotic epithelium and develop when a portion of the amnion becomes entrapped in the formation of the umbilical cord. ${ }^{8,9}$

Pseudocysts, on the other hand, have no epithelial lining and may represent cystic degeneration of Wharton jelly or localized edema. Pseudocysts are also termed as umbilical cord edema, pseudotumor, Wharton's jelly cyst, angiomyxoma, hemangiofibromyxoma and telangiectatic myxosarcoma. ${ }^{7}$ They have been reported to be more common. Pseudocysts may be associated with chromosomal anomalies, omphalocele, hemangiomas and patent urachus. ${ }^{1}$ It is rarely possible to differentiate between true cysts and pseudocysts by sonography only. This can be done only by means of a histopathologic study. But differentiation between the two entities is not very important because both are associated with anomalies. ${ }^{1,2,10,11}$

Single umbilical cord cysts are identified in approximately $1 \%$ of first trimester sonograms Most are isolated and resolve, and are not associated with adverse pregnancy outcomes. ${ }^{12-14}$ Multiple cysts, in contrast, may confer increased risk for spontaneous abortion or aneuploidy. ${ }^{12}$ Cysts persisting into the second or third trimester are associated with an increased risk for fetal abnormalities, particularly omphalocele and patent urachus, and if abnormalities are present, the aneuploidy risk is also increased. ${ }^{15}$ Thus an umbilical cord cyst is an indication for targeted obstetric sonogram. However, if no associated anomalies are identified, the prognosis appears to be favorable. ${ }^{8}$

A higher risk of fetal anomalies is associated with the following: detection of cysts in the second or third trimester, persistence after the first trimester, large size, and location near fetal or placental end. Also, trisomy 18 , 13, and 21 are known to be associated, in such cases, chromosomal analysis may be warranted..$^{5,16}$

Authors made the most probable diagnosis of umbilical cord hemangioma based on its ultrasonographic picture of cystic component along with solid mass with good vascular supply. Statistically, hemangioma is much more common and the location at the placental insertion site is typical. Highly raised alpha feto protein levels and polyhydramnios were also in favour of hemangiomas. Lack of internal calcification ruled out teratoma. Due to large size of the lesion and fear of rupture of same during process of labour, decision for elective LSCS was taken at 39 weeks. Moreover, adverse fetal outcomes such as fetal haemorrhage and fetal death in literature have been reported. ${ }^{17}$ Definative diagnosis was made only after histopathological report of the specimen. Had there been no vascular supply within the lesion and only cystic component on sonogram, LSCS of the patient would have been avoided (probably the presence of blood admixed with mucin present in the cyst) was mimicking the diagnosis of umbilical cord hemangioma antenally on ultrasonographic report. 
Baby had cutaneous hemangiomatosis. Literature has reported umbilical cord hemangiomas and pseudocysts are associated with newborn hemangiomas and not umbilical cord true cysts. So, more studies are needed to correlate exact association between true umbilical cord cysts and neonatal hemangiomas. However, polyhydramnios and raised alpha fetoprotein levels are associated with both umbilical cords cysts and hemangiomas.

\section{CONCLUSION}

Umbilical cord cysts is also a differential diagnosis of umbilical cord hemangiomas (as both showed a solid component along with vascularity on sonogram as in our case) among others. Large size of the lesion and fear of rupture of same (if possibility of hemangioma is kept in mind) can lead to LSCS of the patient. Definative diagnosis may be possible only after birth of the baby. Definative diagnosis between true and pseudocysts of umbilical cord can be made only after histopathological examination.

Funding: No funding sources Conflict of interest: None declared

Ethical approval: Not required

\section{REFERENCES}

1. Morgan BLG, Ross MG. 2006. Umbilical Cord. Complications. (On-line article.) Omaha, Neb: www.emedicine.com. Updated March 1, 2006.

2. Heredia F, Jeanty P. Umbilical Cord Anomalies.

3. Ratan SK, Rattan KN, Kalra R, Maheshwari J, Parihar D, Ratan J. Omphalomesenteric duct cyst as a content of omphalocele. Indian J Pediatr.2007; 74:500-2.

4. Bunch PT, Kline-Fath BM, Imhoff SC, Calvo-Garcia MA, Crombleholme TM, Donnelly LF. Allantoic cyst: a prenatal clue to patent urachus. Pediatr Radiol 2006;36:1090-513.

5. Kilicdag EB, Kilicdag H, Bagis T, Tarim E, Yanik F. Large pseudocyst of the umbilical cord associated with patent urachus. J Obstet Gynaecol Res. 2004; 30:444-7.

6. Iyoob SD, Tsai A, Ruchelli ED, Coleman BG, Wilson RD. Large umbilical cord hemangioma: Sonographic features with surgical pathologic correlation. J Ultrasound Med.2006;25(11):1495-8.
7. Marino T. Ultrasound abnormalities of the amniotic fluid, membranes, umbilical cord, and placenta. Obstetr Gynecol Clinics North Am.2004; 31(1):177200

8. Peter W Callen.Ultrasound evaluation of placenta and umbilical cord: In textbook of ultrasonography in obstetrics and gynaecology: 5th ed. Saunders Elsevier publication;2007:750-54.

9. Bisset lal, Durr-e-Sabih, ed. Differential diagnoisis in obstetrics and gynaecological ultrasound: 3rd ed. Elsevier publication;2013:63-5.

10. Kiran H, Kiran G, Kanber Y. Pseudocyst of the umbilical cord with mucoid degeneration of Wharton's jelly. European J Obstetr Gynecol Reproductive Biol.2003;11(1):91-93.

11. Kinare A. Fetal environment. Indian $\mathbf{J}$ Radiol Imaging. 2008;18(4):326-44.

12. Ghezzi F, Raio L, Di Naro E, Franchi M, Cromi A, Dürig P. Single and multiple umbilical cord cysts in early gestation: two different entities. Ultrasound Obstetr Gynecol. 2003;21(3):215-9.

13. Gilboa Y, Kivilevitch Z, Katorza E, Leshem Y, Borokovski T, Spira M, et al. Outcomes of fetuses with umbilical cord cysts diagnosed during nuchal translucency examination. J Ultrasound Med. 2011;30(11):1547-1.

14. Hannaford K, Reeves S, Wegner E. Umbilical cord cysts in the first trimester: are they associated with pregnancy complications? J Ultrasound Med.2013; 32(5):801-6.

15. Zangen R, Boldes R, Yaffe H, Schwed P, Weiner Z. Umbilical cord cysts in the second and third trimesters: significance and prenatal approach. Ultrasound Obstetr Gynecol. 2010;36(3):296-301.

16. Szpejankowski K, Guzik P, Chechlinski P, Jach R, Ostrowski B. Pseudocyst of the umbilical cord-case report. Med Review. 2015;72(7):394-6.

17. Vougiouklakis T, Mitselou A, Zikopoulos K, Dallas $\mathrm{P}$, Charalabopoulos K. Ruptured hemangioma of the umbilical cord and intrauterine fetal death, with review data. Pathol Res Pract. 2006; 202:537-40.

Cite this article as: Kaushal A, Mehra R, Dubey S, Goel P, Sheokand S, Kaur N. Umbilical cord cyst: a diagnostic dilemma. Int J Reprod Contracept Obstet Gynecol 2019;8:1207-10. 